\title{
Interconnected activated carbon nanofiber derived from mission grass for electrode materials of supercapacitor
}

\author{
Rika Taslim ${ }^{1}$, Muhammad Ihsan Hamdy ${ }^{1}$, Merry Siska ${ }^{1}$, Erman Taer $^{2}$, \\ Deris Afdal Yusra ${ }^{2}$, Apriwandi $^{2}$, Marhama Jelita ${ }^{3}$, Susi Afriani ${ }^{3}$ and \\ Novi Gusnita ${ }^{3}$ \\ ${ }^{1}$ Department of Industrial Engineering, State Islamic University of Sultan Syarif Kasim, 28293 Simpang \\ Baru, Riau, Indonesia \\ ${ }^{2}$ Department of Physics, Faculty of Mathematics and Natural Sciences, University of Riau, 28293 Simpang \\ Baru, Riau, Indonesia \\ ${ }^{3}$ Department of Electrical Engineering, State Islamic University of Sultan Syarif Kasim, 28293 Simpang \\ Baru, Riau, Indonesia
}

E-mail: rikataslim@gmail.com

Received 30 April 2021

Accepted for publication 17 July 2021

Published 4 October 2021

\begin{abstract}
The porous carbon electrode materials for supercapacitors derived from biomass waste attract lots of attention due to their natural abundance and low cost. This study therefore aims at developing a cost-effective and sustainable method for synthesising porous activated carbon derived from mission grass biomass waste (MG). The one-stage integrated pyrolysis for carbonisation, physical activation, and $\mathrm{KOH}$ activation was used to obtain porous activated carbon monolith. The surface morphology and pore structures consist of interconnected activated carbon nanofiber with high carbon content of $90.45 \%$. The KOH impregnation successfully changed the morphology from the rod-like shape into a nanofiber structure. Due to their synergistic effect, the specific capacitance enhanced from 115 to $171 \mathrm{~F} \mathrm{~g}^{-1}$ in $1 \mathrm{M} \mathrm{H}_{2} \mathrm{SO}_{4}$ aqueous electrolyte with an egg duck shell membrane as a separator. The result showed that the maximum energy and power densities were $23.75 \mathrm{Wh} \mathrm{kg}^{-1}$ and $96.94 \mathrm{~W} \mathrm{~kg}^{-1}$, respectively. Therefore, these unique properties enable the mission grass to become a high potential for porous carbon electrode materials as supercapacitor energy storage.
\end{abstract}

Keywords: nanofiber, porous carbon, electrode materials, supercapacitor, energy storage

\section{Introduction}

Energy is a basic necessity for humans all over the world, as well as water and food. Its consumption tends to increase significantly every year, thereby lowering the availability of fossil fuels as the main energy source. This led to the development of numerous renewable energy technologies such as solar cells, turbines, and wind power, as an alternative electricity generation. The availability of these resources is still limited, therefore, storage devices with high energy and power densities, as well as excellent rate performance such as batteries, supercapacitors, and electrolyte capacitor are needed $[1,2]$. Furthermore, supercapacitor is a type of energy storage device that is considered to have high performance due to their relatively higher energy density than capacitors and greater power density than batteries [3, 4]. The electrode material is the main substance used in the production of highperformance supercapacitors, including electric double-layer capacitors (EDLC) and pseudo-capacitor [3, 5]. Due to the high surface area, better electrical conductivity, and more stable electrochemical properties of porous carbon, it is defined as the ideal electrode material for EDLC [6]. The porous carbon materials often used are nanotubes, activated carbon, graphene [7], and metal-organic [5, 8]. Conversely, the electrodes for pseudo-capacitive material used to store high energy from redox reactions are derived from metal 
oxide transitions [9] and conductive polymers [10]. All electrode materials from both types of supercapacitors have superior properties such as numerous pore structures, highly accessible surface areas, and unique nanostructure morphology. These features contribute to provide abundant pathways for ion diffusion, more massive active sites for electrochemical reactions, and enhanced energy output [3, 11-13]. However, there are challenges associated with the preparation of supercapacitor electrodes such as its expensive cost, complex synthetic materials, multi-step preparation methods, and relatively complicated.

Presently, many studies reported the potential of biomass as an active carbon base material for supercapacitor electrodes with relatively low-cost preparation and environmental advantages [14-16]. In addition, the basic components of biomass such as $\mathrm{C}, \mathrm{H}, \mathrm{O}$ and $\mathrm{N}$ elements provide a significant advantage in the pseudo-capacitive behaviour. In addition, biomass raw material has a unique morphological structure of complex lignocellulose compounds such as nanomaterial including nanofiber, nanosheet, and nanospheres, as well as the interconnection between micro, meso and macroporous [17-19]. The synergy of these benefits increases energy in EDLC. For example, nanofiber and nanosheet structures were obtained from leaves-based with specific capacitance range of 25-150 $\mathrm{F} \mathrm{g}^{-1}[20,21]$. In addition, Wang et al converted pinewood to activated carbon nanofiber via solar pyrolysis which produces an excellent specific capacitance of $349 \mathrm{~F} \mathrm{~g}^{-1}$ [22]. However, all of biomass wastes do not always exhibit nanostructures of porous carbon materials for supercapacitor. Therefore, it is necessary to know the potential biomasses that contain an effective lignocellulose content to produce nanostructure materials.

Mission grass (Pennisetum polystachyon) is one of the weeds commonly found in Indonesia, Philippines, Thailand, and Malaysia. This plant belongs to the Poaceae family and grows wildly. In Indonesia, mission grass is widely cultivated for livestock feed purposes, and it is rich in lignocellulose complex compounds and consists of $39.8 \%-40.0 \%$ cellulose, $23.3 \%-29.2 \%$ hemicellulose, $6.2 \%-14.6 \%$ lignin, and $3.3 \%-7.5 \%$ ash [23]. Therefore, it is potentially converted as activated carbon to supercapacitor electrodes.

This study aims to convert mission grass waste into interconnected macroporous and mesoporous carbon using effective-cost, simple methods for supercapacitor electrodes as high-performance energy storage devices. One of the stage integrated pyrolysis used for both carbonization and physical activation is $\mathrm{KOH}$ impregnation, which is selected to convert lignocellulose mission grass into activated carbon. Electrodes were then fabricated in the coin type with $1 \mathrm{M} \mathrm{H}_{2} \mathrm{SO}_{4}$ as aqueous electrolyte. The results showed that the activated carbon exhibits interconnected macropore and mesopore structures. Furthermore, the $\mathrm{KOH}$ impregnation successfully changes the morphology structure from the rod-like shape into the nanofiber. The symmetric capacitor double layers show maximum specific capacitance of $171 \mathrm{~F} \mathrm{~g}^{-1}$ at a scan rate of $1 \mathrm{mV} \mathrm{s}^{-1}$ in a two-electrode system. These unique properties enable the mission grass to become a high potential for porous carbon electrode materials as supercapacitor energy storage.

\section{Experimental section}

\subsection{Preparation of porous carbon monolith}

The mission grass (MG) waste is collected from swampy areas located in Pekanbaru, Riau Province. This biomass waste is cut and cleaned with distilled water and dried in an oven at $110{ }^{\circ} \mathrm{C}$. Approximately $30 \mathrm{~g}$ of the sample is precarbonised in an oven at $250{ }^{\circ} \mathrm{C}$ and converted into powder using ball milling. Furthermore, the pre-carbonised powder samples were impregnated with $\mathrm{KOH}$ solution using three different concentrations of $0.3,0.5$, and $0.7 \mathrm{M}$ in a hot plate at a temperature of $80{ }^{\circ} \mathrm{C}$ and $300 \mathrm{rpm}$. These different concentrations produced samples of MG0.3, MG0.5, and MG0.7, respectively, which are dried after 2 days. Carbon powder is converted into the monolith form using a hydraulic press with the one-stage pyrolysis at room temperature to a maximum temperature of $600{ }^{\circ} \mathrm{C}$ in an $\mathrm{N}_{2}$ gas environment, followed by the physical activation at high temperature of $850{ }^{\circ} \mathrm{C}$ at a $\mathrm{CO}_{2}$ gas atmosphere. Finally, the carbon monolith samples were neutralized using distilled water.

\subsection{Materials characterisation}

The density analysis was evaluated in accordance with the dimension, mass, and volume of porous carbon monolith. Thermal analysis was carried out using thermogravimetric analysis (TG/DTG) and Shimadzu TGA-50 at heating and flow rates of $10{ }^{\circ} \mathrm{C} \mathrm{min}{ }^{-1}$ and $100 \mathrm{ml} \mathrm{min}^{-1}$, respectively in $\mathrm{N}_{2}$ atmosphere. The degree of crystallinity of the carbon monolith was characterized by powder X-ray diffraction (XRD) method using the Phillip X-Pert Pro PW3060/10 instrument at a $\mathrm{Cu}-K_{\alpha}$ radiation. In addition, the surface morphology and chemical composition of the samples were investigated to determine their scanning electron microscopy and energy dispersive spectroscopy (EDS) using the JEOLJSM-6510LA instrument with an applied voltage of $15 \mathrm{kV}$. The porosity properties of the samples were reviewed using $\mathrm{N}_{2}$ gas adsorption/desorption analysis with a Quantachrome TouchWin Version 1.2 instrument at degassing temperature of $300{ }^{\circ} \mathrm{C}$.

\subsection{Electrochemical measurement}

The electrochemical performances of porous carbon monolith as supercapacitor electrodes were evaluated in the cyclic voltammetry (CV) by using a CV UR Rad-Er 5841 instrument calibrated by VersaStat II Princeton Applied Research, at an error rate of $\pm 6.05 \%$. Furthermore, the evaluated supercapacitor cell consists of a porous carbon monolith in the two-electrode system of $1 \mathrm{M} \mathrm{H}_{2} \mathrm{SO}_{4}$ as an electrolyte assembled in coin type. The membrane egg duck shell was selected as a separator with the specific capacitance evaluated by using the standard equation. The potential window was 


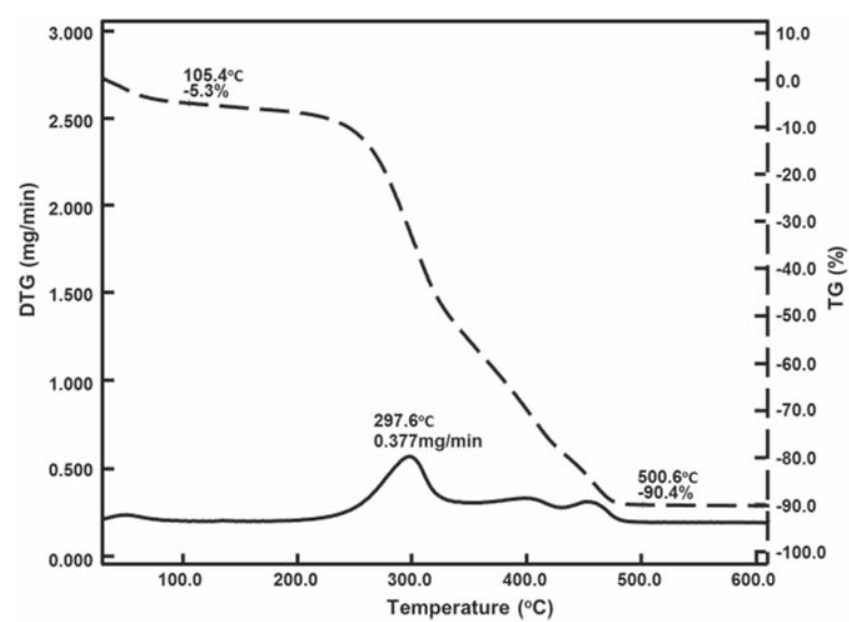

Figure 1. TG/DTG curve for pre-carbonised mission grass powder.

applied in a range of $0-1 \mathrm{~V}$ in different scanning rates of 1,2 , 5 , and $10 \mathrm{mV} \mathrm{s}^{-1}$.

\section{Result and discussion}

\subsection{Thermal analysis}

The carbonization process is an important factor used to convert biomass into porous carbon materials. Its temperature has a large influence on the pyrolysis process, and it is an essential factor in determining the carbon content of decomposed lignocellulose. The temperature suitable for the carbonization of porous carbon in the $\mathrm{N}_{2}$ atmosphere was investigated using the TG/DTG analysis, as shown in figure 1. The differential thermal analysis/DTG shows two stages of significant weight loss with an increase in temperature. In the first stage, a weightloss of $5.3 \%$ at a temperature of $105.4{ }^{\circ} \mathrm{C}$ was obtained with a drying and preheating stage caused by moisture evaporation $[24,25]$. The second stage of weight-loss is found in the temperature range of $250{ }^{\circ} \mathrm{C}-500{ }^{\circ} \mathrm{C}$ at $85.1 \%$. This stage correlates with the decomposition of lignocellulose compounds, including hemicellulose, cellulose, and lignin at different temperature ranges of $150{ }^{\circ} \mathrm{C}-215^{\circ} \mathrm{C}$ [26]. Furthermore, the temperature of thermal degradation for cellulose is higher in the range of $300{ }^{\circ} \mathrm{C}-400{ }^{\circ} \mathrm{C}$ due to its regular structure and good thermal stability. In addition, cellulose has a relatively homogeneous unit, therefore, the pyrolysis temperature range is relatively narrow, at approximately $100{ }^{\circ} \mathrm{C}$, capable of producing more volatile matters within a short time and less amount of solid residues [27, 28]. However, the lignin compound was decomposed in the high-temperature range of $190{ }^{\circ} \mathrm{C}-900{ }^{\circ} \mathrm{C}$, and at $600{ }^{\circ} \mathrm{C}$ no further significant decrease was observed, with a total weight loss of $90.4 \%$ [28]. This phenomenon shows that the optimal carbonisation temperature of the activated carbon preparation is $600{ }^{\circ} \mathrm{C}$.

Furthermore, the thermal gravimetry (TG) profile shows the rate of weight loss of the sample with increasing temperature. The instrument does not indicate a significant peak from room temperature to $250{ }^{\circ} \mathrm{C}$. The rate of weight loss

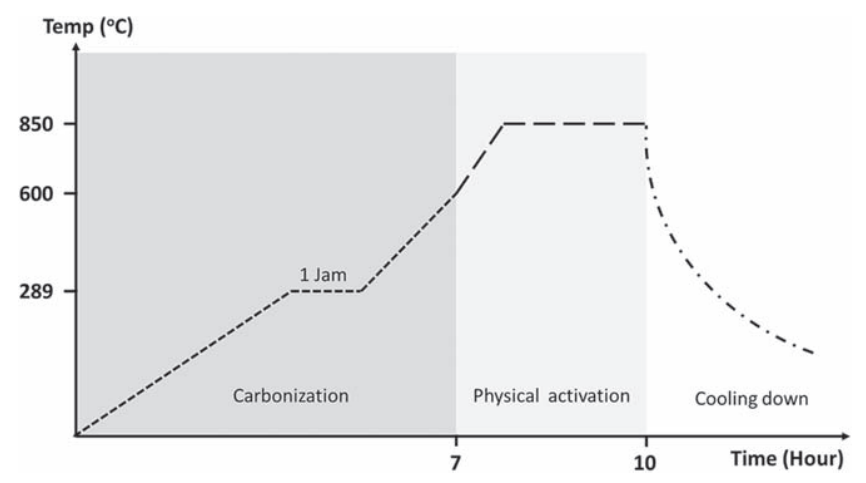

Figure 2. Profile of the one-stage integrated pyrolysis process.

dramatically increases from 250 to $297.6{ }^{\circ} \mathrm{C}$ at $0.377 \mathrm{mg}$ $\min ^{-1}$. This phenomenon is indicated by the degradation of lignocellulose compounds, which occurs simultaneously $[27,28]$. Hemicellulose, cellulose, and lignin are maximally decomposed, thereby creating the most significant weight loss. In the second stage, this analysis is related to DTG. Further temperature increases are no longer observed due to the rise in mass loss. Therefore, an initial temperature of $297.6{ }^{\circ} \mathrm{C}$ was used for $1 \mathrm{~h}$ during the carbonization process. The selection of initial and maximum carbonization temperature is expected to decompose lignocellulose compounds and modify the structure of porous carbon, which is advantageous for the performance of supercapacitor electrodes. Figure 2 shows a detailed analysis of the carbonization and physical activation of the pyrolysis process.

\subsection{Density and degree of crystallinity behaviour}

The one-stage integrated pyrolysis process for the carbonization and physical activation of carbon has a profound effect on physicochemical properties, which includes porous monolith. Density is the initial analysis of physical properties obtained at the end of the pyrolysis and chemical activation processes. The carbonization and physical activation of the pyrolysis process gradually reduces the density of monolith carbon, as shown in figure 3(a). The carbonization from room temperature to a maximum temperature of $600{ }^{\circ} \mathrm{C}$ reduces and decomposes all complex compounds, including moisture, hemicellulose, cellulose, and lignin in the TG/DTG analysis. This process allows an increased carbon content and provides porosity effect on carbon monoliths, thereby reducing mass and volume. However, the co-product of carbonization in the form of solid tar covers the formed pores. Therefore, it is necessary to activate it with high temperature [29]. Physical activation from a temperature of $600{ }^{\circ} \mathrm{C}-850{ }^{\circ} \mathrm{C}$ eliminates co-product carbonization that covers the pore and exhibits a relatively better pore structure [19, 29].

In addition, it is also possible to produce interconnected pores such as meso and macropores. This phenomenon reduces the density of porous carbon monoliths and enhances the performances of supercapacitor electrodes. Figure 3(a) shows that all samples have decreased density at the end of the one-stage pyrolysis process. Furthermore, three different $\mathrm{KOH}$ activators, namely $0.3,0.5$, and $0.7 \mathrm{M}$ applied in all 
(a)

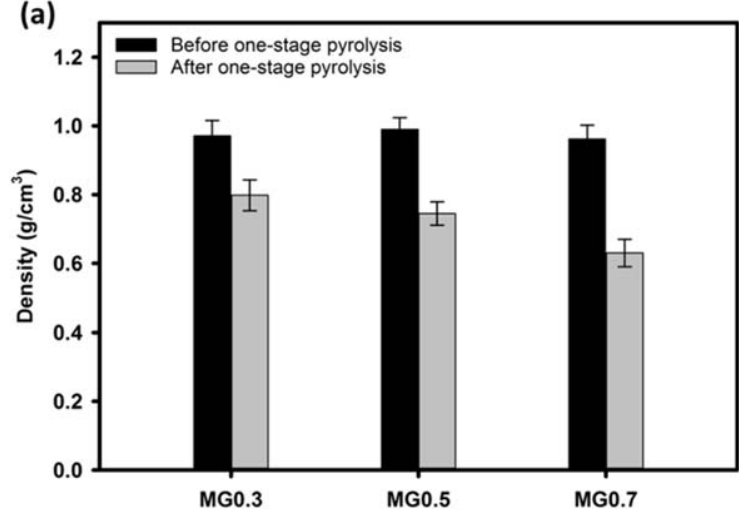

(b)

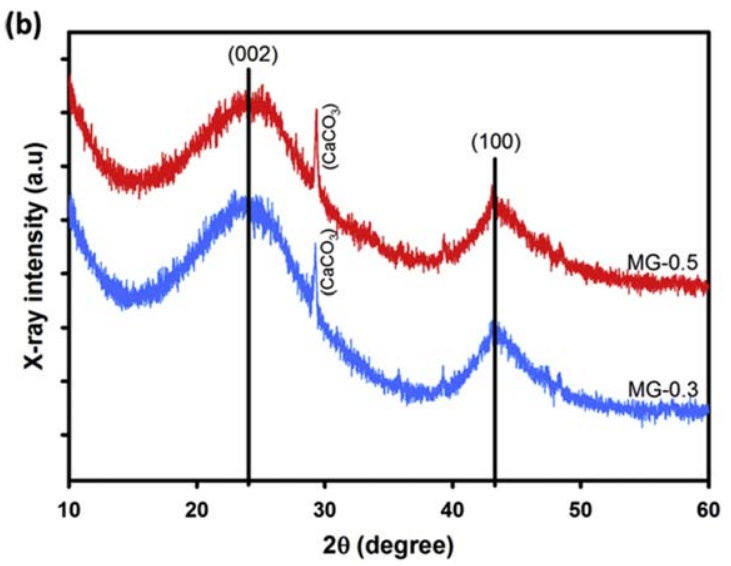

Figure 3. (a) Density of porous carbon, (b) XRD pattern of porous carbon.

samples, showed a significant effect on density. The addition of $\mathrm{KOH}$ concentrations from 0.3 to $0.7 \mathrm{M}$ has the ability to reduce the density from 25 to $46 \%$, thereby creating more connected pores in the porous carbon monoliths [30]. This analysis correlates with the use of SEM and $\mathrm{N}_{2}$ gas adsorption described in the following subsection.

The crystal structures of porous carbon monolith were analysed using the XRD pattern. This created a significant broad peaks at $2 \theta=23.2^{\circ}-25.3^{\circ}$ and $44.5^{\circ}-45.7^{\circ}$ which corresponded to (002) and (100) reflections in both MG0.3 and MG0.5 samples with a typical carbon characteristic of JCPDS No. 41-1487. This result is similar to other reports such as porous carbon derived from baobab fruit shell [31], banana stem [30], and argan [32] which showed the appearance of broadening peaks at 23 and $43^{\circ}, 24$ and $44^{\circ}$, and 25 and $43^{\circ}$, respectively. All broad peaks showed a typical amorphous carbon structure. However, the broadness of XRD peaks was found to largely shift at (002) diffraction from 23.2 to 25.3 in the MG0.5 when compared with MG0.3. The carbon structure is more amorphous by $\mathrm{KOH}$ activation at a higher concentration from 0.3 to $0.5 \mathrm{M}$, and this result correlated with SEM analysis to produce more interconnected meso- and macropores in MG0.5 porous carbon monolith. Furthermore, the XRD pattern also observed a sharp peak at $2 \theta$ of $29.6^{\circ}$, which indicated the presence of calcium carbonate $\left(\mathrm{CaCO}_{3}\right)$ (JCPDS No. 82-1690) in both MG0.3 and MG0.5. Meanwhile, more addition of $\mathrm{KOH}$ concentrations from 0.3 to $0.5 \mathrm{M}$ reduces the $\mathrm{CaCO}_{3}$ compound in porous carbon monolith, with a higher concentration in MG0.5 XRD pattern. This existence is extracted from the common content of calcium in biomass materials, which is confirmed by EDS analysis.

\subsection{Surface morphology and porous properties}

The surface morphology and pore structure of porous carbon monolith derived from mission grass biomass waste material are characterised by scanning electron microscopy, as shown in figure 4. The pyrolysis process and impregnation of the chemical reagent are used to change and control the surface morphology. Furthermore, the one-stage integrated pyrolysis, as well as the carbonisation and physical activation processes, is used as the binding chains of the lignocellulose components to separate hemicellulose and lignin from the cellulose contents. The original shape of cellulose is rod-like, and at high temperatures, it has the potential to be microfiber and nanofiber [33], while hemicellulose and lignin tend to form globular morphology [16, 33, 34]. At high temperature, the activation process has the potential to form nanosheet and nanosphere structures, as previously reported [35, 36]. Furthermore, $\mathrm{KOH}$ activation is beneficial for larger SSA with suitable porous and interconnected pore structure. These benefits are contributing factors as the ion pathways for higher powers and specific capacitance supercapacitor electrode [37, 38].

The SEM micrograph of MG0.3 and MG0.5 samples showed that similar morphology consists of the carbonaceous fragments with irregular sizes, ranging from several hundreds of micrometers, as shown in figures 4(a) and (b). Furthermore, MG0.3 sample exhibited a structure of the aggregated porous-flakes with apparent macropores. The thermochemical decomposition of $\mathrm{KOH}$ causes the etching of solid carbon chains in the sample and produces morphology flaky-like shapes with macropores in a range of $234 \mathrm{~nm}$, as shown in figure 4(b). In addition, the morphology of a short rod-like shape has a diameter of $23 \mathrm{~nm}$.

Figure 4(c) showed rougher and hollow-fiber samples of MG0.3 and MG0.5 with clear macropore and mesopore structures. In particular, there are many sub-macropores in this amorphous structure, therefore, the addition of $\mathrm{KOH}$ concentration has the ability to modify the structure and morphology of porous carbon monoliths. The MG0.5 pyrolysed at high temperatures obtained hierarchical interconnected porous structures, as shown in figure 4(d), however, undeveloped micropores, as seen in the pore distribution curves. An increase in $\mathrm{KOH}$ concentration to $0.5 \mathrm{M}$ creates more carbon chains and widens the pores due to hightemperature pyrolysis, and obtains interconnected pores hierarchically. In addition, microfiber structures are also found on GM0.5 samples due to the addition of $\mathrm{KOH}$ activator, which decomposes the hemicellulose and lignin attached to cellulose and further reduces the size of rod-like cellulose to microfiber. This interconnected mesopores and 

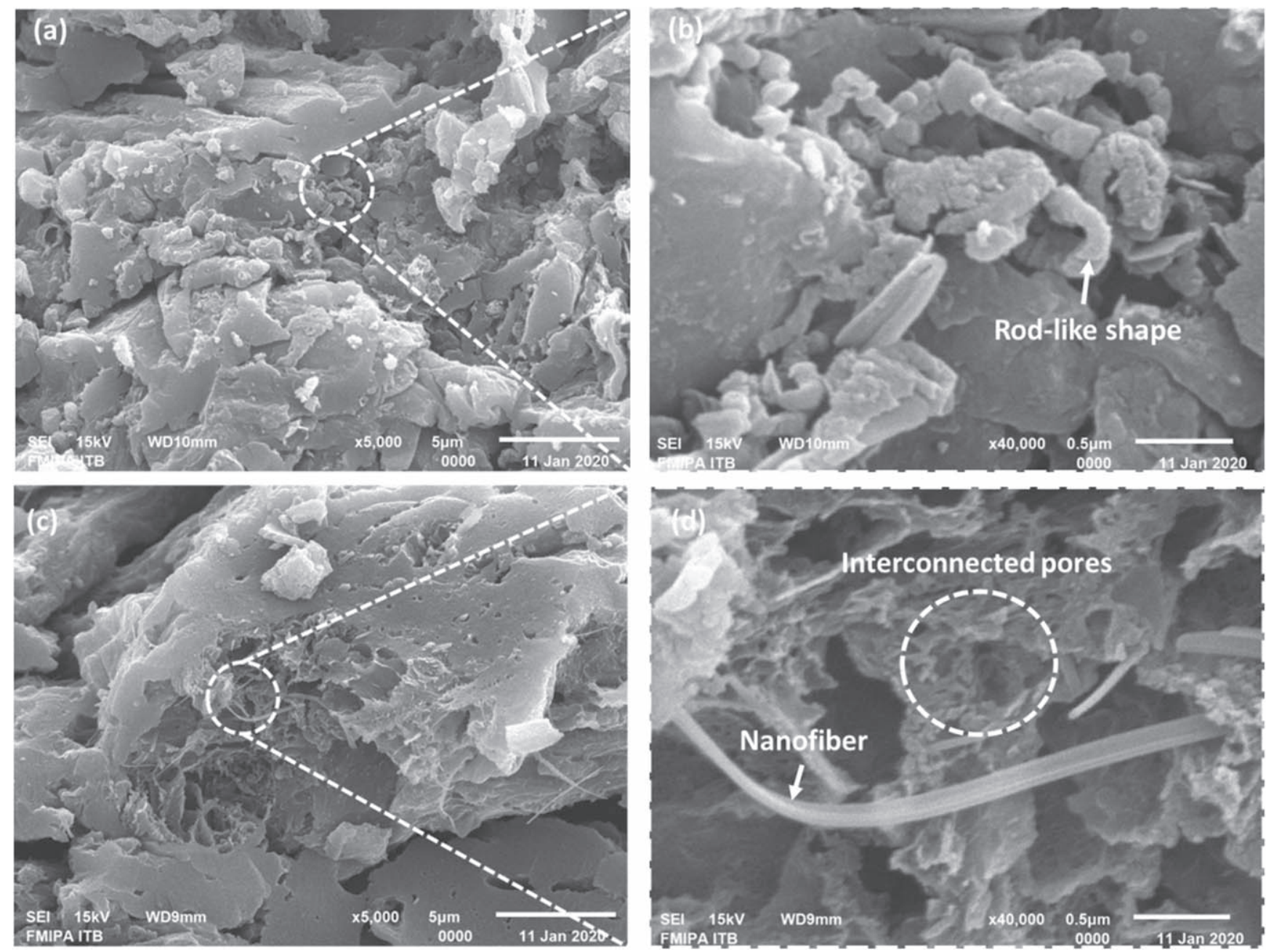

Figure 4. SEM images for (a) MG0.3, (b) enlarge of MG0.3, (c) MG0.5, (d) enlarge of MG0.5.

macropores with decorated microfiber structures make a high contribution to the surface area, and ion transfer on the electrode/electrolyte interface, thereby increasing the supercapacitor performance, as confirmed by the analysis of $\mathrm{N}_{2}$ gas absorption and the cyclic voltammetry curve. In general, there is a unique interconnection between mesopore and macropore structures, which interacts with MG biomass, one-stage pyrolysis, and $\mathrm{KOH}$ activation, thereby, producing a carbon framework and small gas molecules of $\mathrm{H}_{2} \mathrm{O}, \mathrm{CO}_{2}$, and $\mathrm{CO}$ [27], to form micropores. However, when carbon is pyrolysed at high temperatures in one stage, its micropores are integrated with larger sizes destroyed to form stable structures of distributed mesopores and macropores. This unique structure is far more useful for the transportation and storage of electrolyte ions, thereby increasing the performance of supercapacitor electrodes.

Figure 5(a) shows the $\mathrm{N}_{2}$ gas adsorption/desorption curves for MG0.3 and MG-0.5 samples used to observe the porous behaviour of carbon monolith. Generally, both MG0.3 and MG-0.5 profiles exhibit a combination of types I and IV based on IUPAC classification [39]. The significant increase of $\mathrm{N}_{2}$ gas adsorption at a relative low pressure of $P / P_{0}<0.1$ suggests a small amount of microporous structure
[40]. The hysteresis loop with a typical $\mathrm{H} 4$ type at a relative pressure of $P / P_{0}=0.4-0.95$ indicates the presence of numerous mesopores [41]. However, all samples do not show an ideal $\mathrm{H} 4$ type of hysteresis because at a relative pressure $P / P_{0}<0.4$, the desorption line fails to blend with the adsorption, which indicates that the presence of $\mathrm{N}_{2}$ gas is trapped in the carbon monolith pores [42]. This phenomenon is caused by the formation of like-bottle pores, which have a narrow pore neck enabling it to hold the $\mathrm{N}_{2}$ gas till the desorption process is complete [43]. Furthermore, the MG-0.5 sample showed a significant increase in the relatively high pressure of $P / P_{0}=0.9-0.98$, indicating that there are a lot of macropores not found in the MG-03 sample. The specific surface area for both samples was evaluated using the BET method of 152.072 and $266.159 \mathrm{~m} \mathrm{~g}^{-1}$ for MG-0.3 and MG0.5 samples, respectively. The addition of $\mathrm{KOH}$ concentrations from 0.3 to $0.5 \mathrm{M}$ increased the specific surface area and affected the number of carbon monolith pore combinations confirmed by the $\mathrm{N}_{2}$ gas absorption profile. In the MG-0.5 sample, real interconnected pores are formed, which comprise micropores, mesopores, and macropores, which are not found in MG0.3. These pore combinations greatly contribute to 

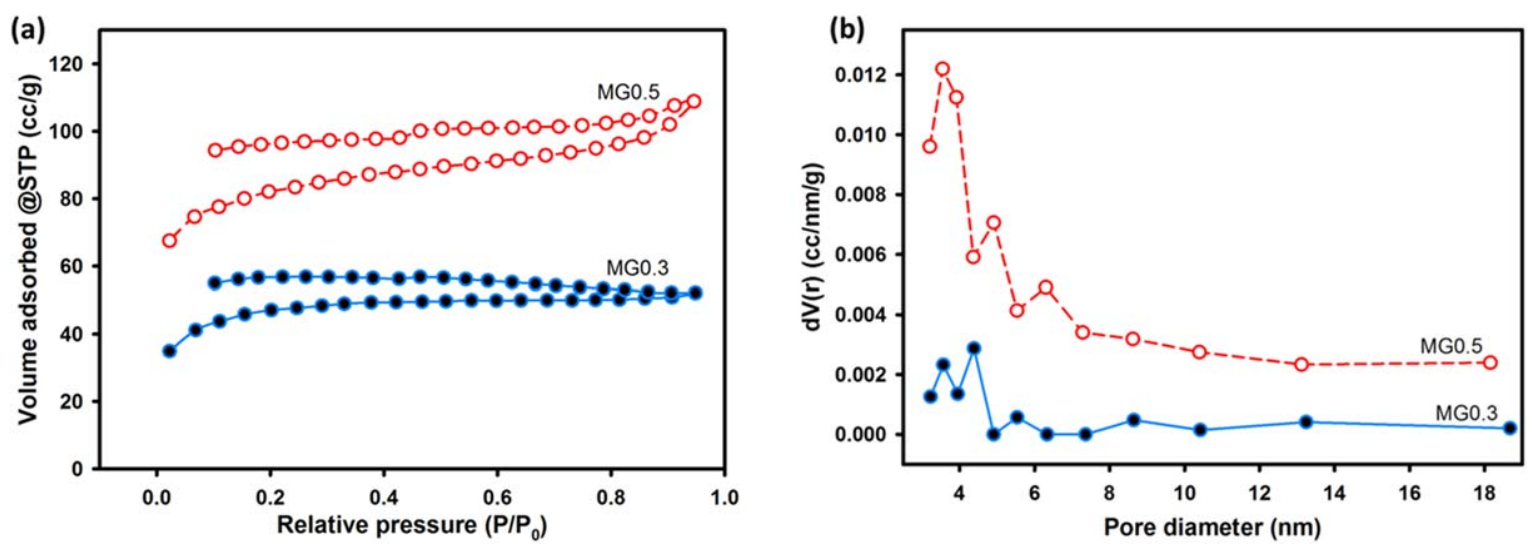

Figure 5. (a) $\mathrm{N}_{2}$ gas adsorption curve of MG0.3 and MG0.5, (b) Pore size distribution of MG0.3 and MG0.5.

Table 1. The chemical composition of both MG-0.3 and MG-0.5 samples.

\begin{tabular}{lcccccc}
\hline Element contents & $\mathrm{C} \mathrm{( \% )}$ & $\mathrm{O}(\%)$ & $\mathrm{Na}(\%)$ & $\mathrm{Si}(\%)$ & $\mathrm{K}(\%)$ & $\mathrm{Ca}(\%)$ \\
\hline MG0.3 & 88.41 & 9.47 & 0.54 & 0.85 & 0.46 & 0.28 \\
MG0.5 & 90.45 & 7.67 & 0.55 & 0.23 & 0.90 & 0.20 \\
\hline
\end{tabular}

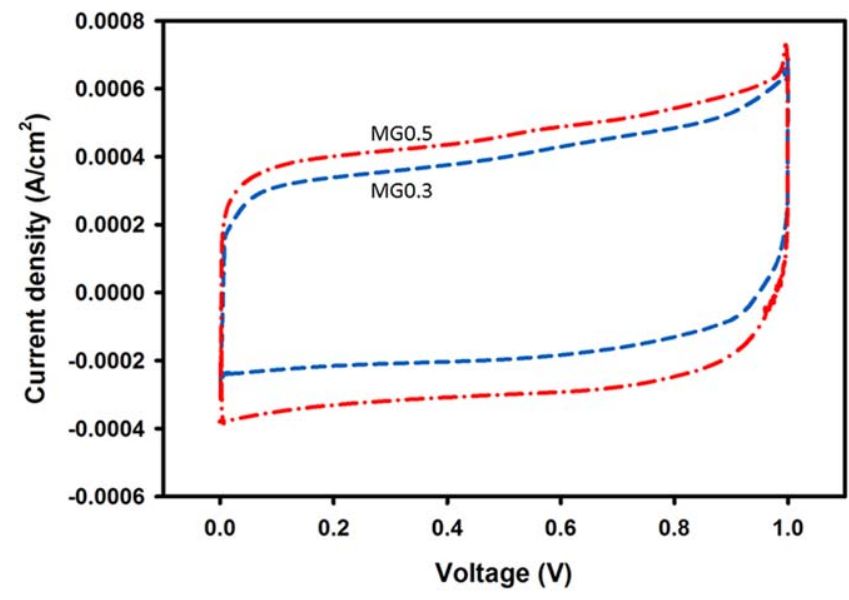

Figure 6. CV curve for MG-0.3, MG-0.5, and MG-0.7 samples.

Table 2. The specific capacitance, energy, and power densities of MG0.3 and MG0.5 supercapacitor cells.

\begin{tabular}{lccc}
\hline Supercapacitor cells & $C_{s p}\left(\mathrm{~F} \mathrm{~g}^{-1}\right)$ & $E\left(\mathrm{Wh} \mathrm{kg}^{-1}\right)$ & $P\left(\mathrm{~W} \mathrm{~kg}^{-1}\right)$ \\
\hline MG0.3 & 115 & 15.97 & 57.55 \\
MG0.5 & 171 & 23.75 & 85.58 \\
\hline
\end{tabular}

providing electrolyte ion active sites, thereby increasing the ion diffusion rate into the electrode interface [44].

These results confirmed the presence of XRD and SEM analyses. In addition, the pore distribution was evaluated using the BJH method for MG0.3 and MG0.5 samples. Figure 5(b) shows the pore diameter distribution profiles, both samples confirm mesopore size in the range of 3 to $20 \mathrm{~nm}$. Furthermore, the addition of $\mathrm{KOH}$ concentration increases the average pore diameter from 3.2 to $3.5 \mathrm{~nm}$ for MG0.3 and MG0.5 samples. Conversely, the presence of mesopores in
MG0.5 samples is greater than in MG0.3, which has the ability to increase the surface area and interconnection in all pores.

\subsection{Energy dispersive spectroscopy analysis}

Furthermore, the chemical composition of MG0.3 and MG0.5 was reviewed by using energy dispersive spectroscopy (EDS), which was summarised in table 1. The porous carbon monolith preparation derived from mission grass waste successfully exhibited high carbon content at a percentage of $88.41 \%-90.45 \%$. The increasing $\mathrm{KOH}$ concentration showed no significant effect on the percentage of carbon content.

Oxygen is the highest element after carbon, with a percentage of $7.67 \%-9.47 \%$, which influences the hydrophilic behaviour [45]. The other elements are also found in a relatively low percentage such as sodium, silica, potassium, and calcium, which are related to compounds commonly found in biomass as raw materials [46]. The results obtained at EDS correlate with several previous reports that use biomass as a raw material of carbon monoliths such as bamboo [47], pineapple leaves [48], rice husk [49], and banana stem [30].

\subsection{Electrochemical properties}

The electrochemical behaviours and capacitive performances of the carbon electrodes derived from mission grass waste were evaluated in the two systems using $1 \mathrm{M} \mathrm{H}_{2} \mathrm{SO}_{4}$ electrolyte with potential windows of $0-1 \mathrm{~V}$. Figure 6 shows the cyclic voltammetry (CV) profiles of MG0.3 and MG0.5 at a scan rate of $1 \mathrm{mV} \mathrm{s}^{-1}$. All the profiles exhibit quasi-rectangular shapes, thereby leading to an ideal symmetric capacitor double-layer behaviour [50]. Furthermore, the area of quasirectangular shape indicates the specific capacitance of the 

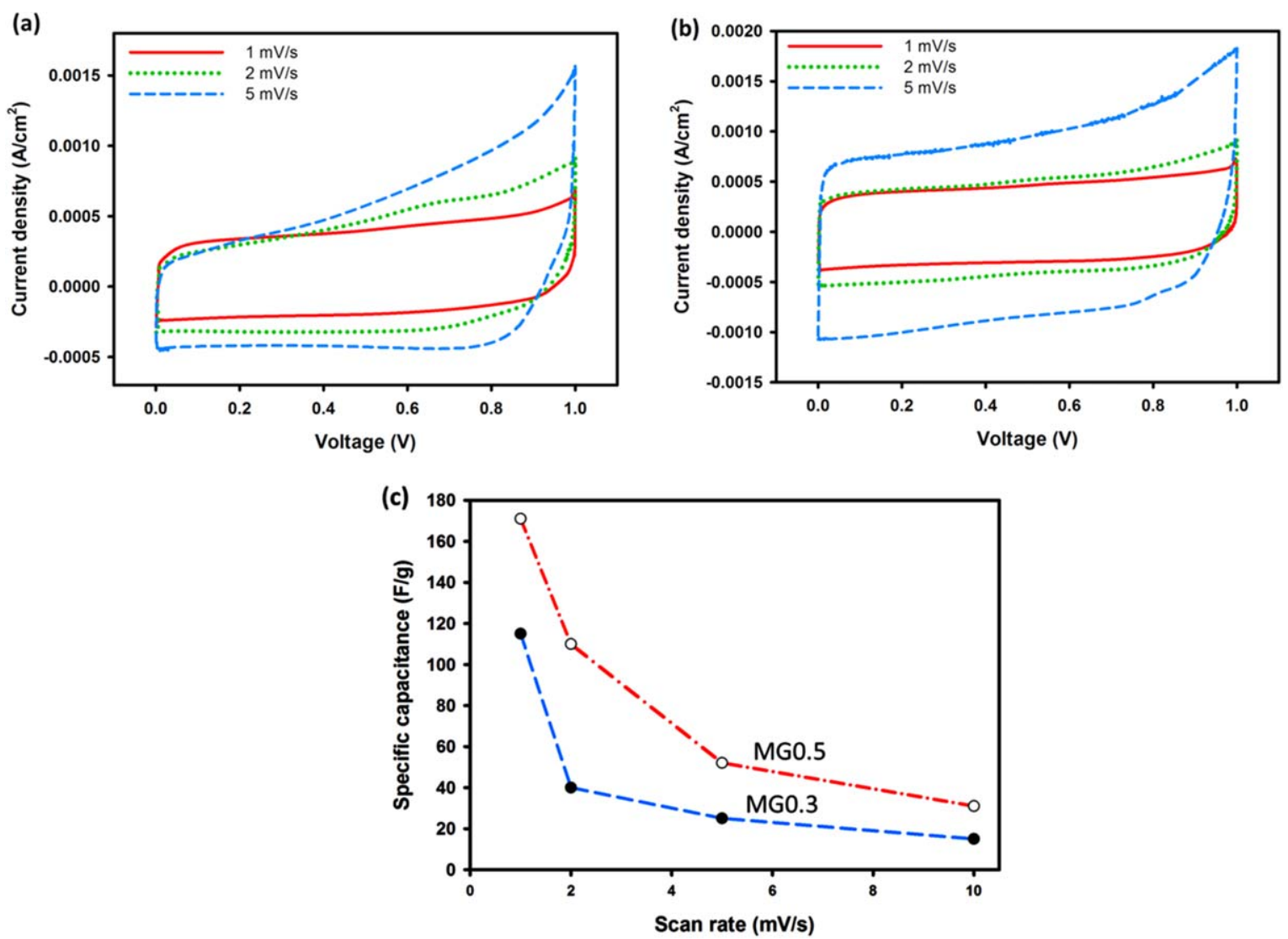

Figure 7. CV curve at various scan rates of (a) MG0.3, (b) MG0.5, and (c) specific capacitance versus scan rate variations for all samples.

Table 3. The comparing the electrochemical behaviour with other carbon-based.

\begin{tabular}{llccc}
\hline \multicolumn{1}{c}{ Sources } & Morphological structure & $C_{\text {sp }}\left(\mathrm{F} \mathrm{g}^{-1}\right)$ & Electrolyte & References \\
\hline Banana steam & Nanofiber & 74 & $1 \mathrm{M} \mathrm{Na}_{2} \mathrm{SO}_{4}$ & {$[53]$} \\
Waste shaddock & Hierarchical porous & 148 & $1 \mathrm{M} \mathrm{H}_{2} \mathrm{SO}_{4}$ & {$[54]$} \\
Cattail fiber & Nanofiber & 38.59 & $1 \mathrm{M} \mathrm{H}_{2} \mathrm{SO}_{4}$ & {$[55]$} \\
Mangosteen peel & Stone & 114.8 & $6 \mathrm{M} \mathrm{KOH}$ & {$[56]$} \\
American poplar fruit & Tubular-like & 58.71 & $6 \mathrm{M} \mathrm{KOH}$ & {$[57]$} \\
Chitin seafood & Nanofiber & 95 & $6 \mathrm{M} \mathrm{KOH}^{2}$ & {$[58]$} \\
Pineapple crown & Nanofiber & 150 & $1 \mathrm{M} \mathrm{H}_{2} \mathrm{SO}_{4}$ & {$[48]$} \\
Mission grass & Nanofiber & 171 & $1 \mathrm{M} \mathrm{H}_{2} \mathrm{SO}_{4}$ & This work \\
\hline
\end{tabular}

supercapacitor with the samples used to obtain 115 and $171 \mathrm{~F} \mathrm{~g}^{-1}$, respectively. The addition of the $\mathrm{KOH}$ activator concentration exhibits a significant increase in specific capacitance from 115 to $171 \mathrm{~F} \mathrm{~g}^{-1}$. It also effectively forms and changes the pore structure of carbon monoliths with a higher concentration capable of increasing the specific surface area, as confirmed by $\mathrm{N}_{2}$ gas adsorption/desorption analysis. $\mathrm{KOH}$ also allows the formation of macropores and mesopores, as confirmed by SEM analysis. The macropores have the ability to shorten the ion diffusion distance, while the mesopores provide fast ion electrolyte transport and large accessible surface areas for the formation of electrical double layers. This phenomenon causes a significant increase in specific capacitance from sample MG0.3 to MG0.5. This obtained specific capacitance is relatively similar to other sources which are shown in table 3.

The energy and power density of the electrode supercapacitor were evaluated by standard equations (1) and (2) $[51,52]$ based on specific capacitance data, as shown in table 2.

$$
\begin{aligned}
& E=\frac{C_{s p} V^{2}}{7.2}, \\
& P=\frac{3600 E}{\Delta t} .
\end{aligned}
$$

Where $C_{\mathrm{sp}}$ is the specific capacitance, $V$ is the discharge voltage, and $\Delta t$ is the discharge time (s). 
The maximum energy and power density found in the MG0.5 sample were as high as $23.75 \mathrm{Wh} \mathrm{kg}^{-1}$ and $85.58 \mathrm{~W}$ $\mathrm{kg}^{-1}$, respectively. The high energy and power density of the MG0.5 supercapacitor cell are mainly attributed to its high specific capacitance. Therefore, the symmetric supercapacitors based on porous carbon materials possess excellent electrochemical performances.

Figures 7(a) and (b) show the CV curves for samples MG0.3 and MG0.5 in the variation of scan rate ranging from 1 to $10 \mathrm{mV} \mathrm{s}^{-1}$. All samples show rectangular shapes, which show that supercapacitor electrodes have the ability to transport ions relatively fast. A significant increase in the current density was also observed, which is attributed to the unique hierarchical pore structure and good conductivity of the supercapacitor electrodes. Figure 7(c) shows the specific capacitance versus the scan rate variations for all the samples. The increasing scan rates occurred due to the gradual decrease in specific capacitance because of the variety of controlling factors, which include the pore size distribution, a combination of micro- and mesopores, and specific surface areas. This is normally found in electrochemical double-layer capacitors.

\section{Conclusion}

In conclusion, this study analyses the cost-effectiveness associated with the one-stage integrated pyrolysis and $\mathrm{KOH}$ impregnation in the preparation of porous activated carbon derived from mission grass biomass waste. The porous carbon monolith comprises amorphous and interconnected macroporous and mesoporous structures. The study also shows that the addition of $\mathrm{KOH}$ concentration increased the specific surface area from 152.072 to $266.159 \mathrm{~m}^{2} \mathrm{~g}^{-1}$ in the MG0.5 sample. Meanwhile, the symmetric capacitor double layers exhibit a rather high charge storage capacity with a specific capacitance of $171 \mathrm{~F} \mathrm{~g}^{-1}$ at a scan rate of $1 \mathrm{mV} \mathrm{s}^{-1}$ in a twoelectrode system. Furthermore, the MG-0.5 sample shows high energy and power densities of $23.75 \mathrm{Wh} \mathrm{kg}^{-1}$ and $96.94 \mathrm{~W} \mathrm{~kg}^{-1}$, respectively in a coin-type symmetric device. Therefore, the porous carbon derived from mission grass with effective-cost, sustainable, and abundant resource has potential for the supercapacitor energy storage application.

\section{Acknowledgments}

This study was funded by the collaborative grants between universities, State Islamic University of Sultan Syarif Kasim, Riau, contract number: 1244/Un.04/PPK/TL.01/05/2021 with the title 'Synthesis of activated carbon from mission grass as an electrode for a supercapacitor energy storage device'.

\section{References}

[1] Young C, Park T, Yi J W, Kim J, Hossain M S A, Kaneti Y V and Yamauchi Y 2018 ChemSusChem 113546 [2] Zhang S et al 2020 Chem. Eng. J. 396125154
[3] Burke A 2000 J. Power Sources 9137

[4] González A, Goikolea E, Barrena J A and Mysyk R 2016 Renew. Sustain. Energy Rev. 581189

[5] Miller E E, Hua Y and Tezel F H 2018 J. Energy Storage 2030

[6] Young C, Kim J, Kaneti Y V and Yamauchi Y 2018 ACS Appl. Energy Mater. 12007

[7] Chen T, Li M, Zhou L, Ding X, Lin D, Duan T, Yang G, He R and Zhu W 2020 ACS Sustain. Chem. Eng. 86458

[8] Poonam S K, Arora A and Tripathi S K 2019 J. Energy Storage 21801

[9] Tan H, Tang J, Kim J, Kaneti Y V, Kang Y M, Sugahara Y and Yamauchi Y 2019 J. Mater. Chem. A 71380

[10] Iro Z S, Subramani C and Dash S S 2016 Int. J. Electrochem. Sci. 1110628

[11] Zhai Y, Dou Y, Zhao D, Fulvio P F, Mayes R T and Dai S 2011 Adv. Mater. 234828

[12] Li X and Wei B 2013 Nano Energy 2159

[13] Gurmeet S and Amrita P 2015 J. Pharmacogn. Phytochem. $J P P 58$

[14] Abioye A M and Ani F N 2015 Renew. Sustain. Energy Rev. 521282

[15] González-García P 2018 Renew. Sustain. Energy Rev. 821393

[16] Rangabhashiyam S and Balasubramanian P 2019 Ind. Crops Prod. 128405

[17] Li Y, Wang X and Cao M 2018 J. CO Util. 27204

[18] Zhang W L, Xu J H, Hou D X, Yin J, Liu D B, He Y P and Lin H B 2018 J. Colloid Interface Sci. 530338

[19] Azwar E, Wan Mahari W A, Chuah J H, Vo D V N, Ma N L, Lam W H and Lam S S 2018 Int. J. Hydrogen Energy 43 20811

[20] Apriwandi A, Agustino A, Taer E and Taslim R 2020 J. Phys. Conf. Ser. 165516

[21] Taer E, Natalia K, Apriwandi A, Taslim R, Agustino A and Farma R 2020 Adv. Nat. Sci. Nanosci. Nanotechnol. 11025007

[22] Wang T et al 2020 Cell Reports Phys. Sci. 1100079

[23] Tatijarern P, Prasertwasu S, Komalwanich T, Chaisuwan T, Luengnaruemitchai A and Wongkasemjit S 2013 Bioresour. Technol. 143423

[24] Saka C 2012 J. Anal. Appl. Pyrolysis 9521

[25] Qu W, Xu Y, Lu A, Zhang X and Li W 2015 Bioresour. Technol. 189285

[26] Fan Y, Cai Y, Li X, Jiao L, Xia J and Deng X 2017 Energy Convers. Manag. 138106

[27] Gonzalez J, Roma S, Encinar J M and Martı G 2009 J. Anal. Appl. Pyrolysis $\mathbf{8 5} 134$

[28] Uysal T, Duman G, Onal Y, Yasa I and Yanik J 2014 J. Anal. Appl. Pyrolysis $\mathbf{1 0 8} 47$

[29] Yahya M A, Al-qodah Z and Ngah C W Z 2015 Renew. Sustain. Energy Rev. 46218

[30] Taer E, Taslim R, Mustika W S, Kurniasih B, Agustino and Afrianda A Apriwandi 2018 Int. J. Electrochem. Sci. 138428

[31] Mohammed A A, Chen C and Zhu Z 2019 J. Colloid Interface Sci. $\mathbf{5 3 8} 308$

[32] Boujibar O, Ghosh A, Achak O, Chafik T and Ghamouss F 2019 J. Energy Storage 26100958

[33] Jiang W, Pan J and Liu X 2019 J. Power Sources 40913

[34] Deng J, Xiong T, Wang H, Zheng A and Wang Y 2016 ACS Sustain. Chem. Eng. 43750

[35] Cai Y, Luo Y, Dong H, Zhao X, Xiao Y, Liang Y, Hu H, Liu Y and Zheng M 2017 J. Power Sources 353260

[36] Yallappa S, Shivakumar M, Nagashree K L, Dharmaprakash M S, Vinu A and Hegde G 2018 J. Electrochem. Soc. $165 \mathrm{H} 614$

[37] Liu Y, Wang Y, Zhang G, Liu W, Wang D and Dong Y 2016 Mater. Lett. 17660

[38] Xue M, Lu W, Chen C, Tan Y, Li B and Zhang C 2019 Mater. Res. Bull. 112269

[39] Sing K S W 1982 Pure Appl. Chem. 542201 
[40] Ahmed S, Ahmed A and Rafat M 2018 J. Saudi Chem. Soc. 22993

[41] Muniandy L, Adam F, Rahman A and Ng E 2014 Microporous Mesoporous Mater. 197316

[42] Zhang G, Chen Y, Chen Y and Guo H 2018 Mater. Res. Bull. 102391

[43] Ayinla R T, Dennis J O, Zaid H M, Sanusi Y K, Usman F and Adebayo L L 2019 J. Clean. Prod. 2291427

[44] Wang Y, Qu Q, Gao S, Tang G, Liu K, He S and Huang C 2019 Carbon N. Y. 155706

[45] Wei H et al 2020 J. Alloys Compd. 820153111

[46] Contescu C I, Adhikari S P, Gallego N C and Evans N D 2018 J. Carbon Res. 49

[47] Kim C, Lee J, Kim J and Yang K 2006 Korean J. Chem. Eng. 23592

[48] Taer E, Apriwandi A, Ningsih Y S, Taslim R and Agustino A 2019 Int. J. Electrochem. Sci. 142462

[49] Xiao C, Zhang W, Lin H, Tian Y, Li X, Tian Y and Lu H 2019 New Carbon Mater. 34341
[50] Scott K 2016 Electrochemical principles and characterization of bioelectrochemical systems Microbial Electrochemical and Fuel Cells (Newcastle upon Tyne: Elsevier) pp 29-66

[51] Sun Q, Jiang T, Zhao G and Shi J 2019 Int. J. Electrochem. Sci. 141

[52] Men B, Guo P, Sun Y, Tang Y, Chen Y, Pan J and Wan P 2019 J. Mater. Sci. 542446

[53] Subramanian V, Luo C, Stephan A M, Nahm K S, Thomas S and Wei B 2007 J. Phys. Chem. C 1117527

[54] Yang S, Wang S, Liu X and Li L 2019 Carbon N. Y. 147540

[55] Song G G, Yang J, Liu K X, Qin Z and Zheng X C 2021 Diam. Relat. Mater. 111108162

[56] Yang V, Senthil R A, Pan J, Khan A, Osman S, Wang L, Jiang W and Sun Y 2019 J. Electroanal. Chem. 855113616

[57] Kumar T R, Senthil R A, Pan Z, Pan J and Sun Y 2020 J. Energy Storage 32101903

[58] Duan B, Gao X, Yao X, Fang Y, Huang L, Zhou J and Zhang L 2016 Nano Energy 27482 